\title{
Incidence and prevalence of multiple sclerosis in Europe: a systematic review
}

Elaine Kingwell ${ }^{1}$, James J Marriott ${ }^{2 *}$, Nathalie Jetté ${ }^{3,4,5}$, Tamara Pringsheim $^{4,5,6}$, Naila Makhani ${ }^{7}$, Sarah A Morrow ${ }^{8}$, John D Fisk ${ }^{3,9}$, Charity Evans ${ }^{10}$, Sarah Gabrielle Béland ${ }^{11}$, Sophie Kulaga ${ }^{11}$, Jonathan Dykeman ${ }^{3}$, Christina Wolfson ${ }^{12}$, Marcus W Koch ${ }^{4,5}$ and Ruth Ann Marrie ${ }^{2}$

\begin{abstract}
Background: Multiple sclerosis (MS) is the most common cause of neurological disability in young adults worldwide and approximately half of those affected are in Europe. The assessment of differential incidence and prevalence across populations can reveal spatial, temporal and demographic patterns which are important for identifying genetic and environmental factors contributing to MS. However, study methodologies vary and the quality of the methods can influence the estimates. This study aimed to systematically review European studies of incidence and prevalence of MS and to provide a quantitative assessment of their methodological quality.
\end{abstract}

Methods: A comprehensive literature search was performed to obtain all original population-based studies of MS incidence and prevalence in European populations conducted and published between January 1985 and January 2011. Only peer-reviewed full-text articles published in English or French were included. All abstracts were screened for eligibility and two trained reviewers abstracted the data and graded the quality of each study using a tool specifically designed for this study.

Results: There were 123 studies that met the inclusion criteria. The study estimates were highly heterogeneous, even within regions or countries. Quality was generally higher in the more recent studies, which also tended to use current diagnostic criteria. Prevalence and incidence estimates tended to be higher in the more recent studies and were higher in the Nordic countries and in northern regions of the British Isles. With rare exceptions, prevalence and incidence estimates were higher in women with ratios as high as 3:1. Few studies examined ethnicity. Epidemiological data at the national level was uncommon and there were marked geographical disparities in available data, with large areas of Europe unrepresented and other regions well-represented in the literature. Only $37 \%$ of the studies provided standardized estimates.

Conclusions: Despite the breadth of the literature on the epidemiology of MS in Europe, inter-study comparisons are hampered by the lack of standardization. Further research should focus on regions not yet studied and the evaluation of ethnic differences in MS prevalence and incidence. National-level studies using current diagnostic criteria, validated case definitions and similar age- and sex-standardization would allow better geographical comparisons.

Keywords: Multiple sclerosis, Epidemiology, Europe, Incidence, Prevalence

\footnotetext{
* Correspondence: jmarriott@hsc.mb.ca

${ }^{2}$ Department of Internal Medicine, University of Manitoba, Winnipeg, Canada

Full list of author information is available at the end of the article
}

\section{Biomed Central}

(c) 2013 Kingwell et al.; licensee BioMed Central Ltd. This is an Open Access article distributed under the terms of the Creative Commons Attribution License (http://creativecommons.org/licenses/by/2.0), which permits unrestricted use, distribution, and reproduction in any medium, provided the original work is properly cited. 


\section{Background}

Multiple sclerosis (MS) is a chronic inflammatory disease of the central nervous system that typically presents in the third or fourth decade of life. It is estimated that more than 2 million people have MS worldwide and the disease is among the most common causes of neurological disability in young adults [1]. The distribution and frequency of MS are assessed by estimates of prevalence and incidence. These measures provide essential information for health service planning, and can be used to monitor or reveal spatial, temporal and demographic differences in the distribution of disease. Comparisons of incidence and prevalence in different populations support assessments of the relative contribution of genetic and environmental factors in MS aetiology [2].

MS is recognized worldwide, however reported incidence rates (the proportion of new cases during a defined time period) and prevalence (the proportion of the population that has the disease at or during a specified time) vary considerably between regions and populations [1]. The observed patterns appear consistent with differential genetic predispositions and also implicate environmental risk factors that modulate the risk of MS at the population level [3]. Results of meta-analyses suggest that the incidence of MS has increased over time and provide some evidence that this has primarily resulted from an increase in the incidence of MS among women [4-8]. Europe is considered a high prevalence region for MS (defined by Kurtzke as a prevalence $\geq 30 / 100,000$ [9]), containing more than half of the global population of people diagnosed with MS [1]. Nevertheless, a great deal of uncertainty remains about how the risk of MS varies among European populations. The aim of this study was to systematically review the prevalence and incidence of MS across Europe. The quality of the published studies along with the temporal and geographical trends were examined and priority areas for further epidemiological research identified.

\section{Methods}

\section{Study selection}

This review was part of a larger study on the worldwide incidence and prevalence of MS, which included all original population-based studies published in English or French between January 1st 1985 and January 31st 2011. The start date of 1985 was chosen in part because the introduction of magnetic resonance imaging (MRI) at that time substantially influenced the diagnosis of MS and thus the reliability of case definitions for prevalence and incidence studies. A comprehensive literature search was performed as previously described [10]. The search terms 'multiple sclerosis', 'incidence', 'prevalence' and 'epidemiology' were entered in MEDLINE and EMBASE databases (see Additional file 1 for detailed search strat- egies), and review articles and bibliographies of original studies so identified were hand searched for potentially relevant studies. Studies in which all data collection was carried out earlier than January 1st 1985 and those that were reported solely as conference presentations or abstracts were excluded.

Two reviewers (RAM, SK or CW) independently screened the abstracts to assess whether each study met all eligibility criteria. If eligibility could not be ascertained by review of the abstract, the full text of the article was reviewed. All articles that met eligibility criteria by consensus of both reviewers were retained.

\section{Data extraction and quality assessment}

For each article, one trained reviewer abstracted data onto a standardized form, including: study location, prevalence day or period, sources for case ascertainment, diagnostic criteria and average age of the study population. Crude and standardized (when available) prevalence and incidence estimates were documented overall and by sex, region, time period and subgroup as applicable. Extracted data were verified by a second reviewer.

Two reviewers independently assessed the quality of each study using a tool designed for this review (Additional file 2) and based on a scoring system suggested by Boyle [1]. The questions aimed to evaluate: the validity of the chosen diagnostic criteria, the representativeness of the study population, the inclusion of confidence intervals, how well the study population was defined, and the reliability and completeness of the data. Each study was scored out of 7 or 8 points based on one potential affirmative score per question. One question applied only to studies that used health administrative data sources; these studies were scored out of 8 while studies using multiple sources of ascertainment were scored out of 7 . Conflicts were resolved by consensus. Data abstraction and quality reviews were conducted using the web-based DistillerSR program (Evidence Partners, Ottawa, Canada).

All European studies were then selected to facilitate detailed examination; Russia was included but Turkey, Kazakhstan, Azerbaijan and Georgia were not (these are included in a separate review of studies from Asia; in preparation). The studies were grouped into eight regions to allow more descriptive analysis: the Italian Peninsula and Malta; the British Isles; the Nordic region; the Iberian Peninsula; Belgium and France; the Central European countries; South East Europe; and the Baltic states, including Russia. All data extracted from the European studies were manually verified by one reviewer (EK). Where possible, female to male prevalence and incidence ratios were calculated from reported data whenever sex ratios were not explicitly reported in the manuscripts. 
Heterogeneity estimates were generated for the prevalence studies for each European region and for all European studies combined. Studies that did not report either the crude estimate with the confidence interval or the number of cases and the population denominator were excluded from these calculations. We examined the resulting $\mathrm{I}^{2}$ statistic, which describes the proportion of variation in point estimates due to heterogeneity between studies rather than to sampling error; a $\chi^{2}$ test of homogeneity was conducted to determine the strength of evidence that heterogeneity was genuine.

\section{Results}

The initial global literature search yielded 3,256 citations through EMBASE and MEDLINE, and a further 16 refer- ences identified by hand searches (see Figure 1). Thirtythree European studies were excluded because of language (eight from Spain, seven from Russia, five from Poland, three Norwegian, three Ukrainian, two German, one Danish, one Czech, one Slovakian, one Serbian and one from the former Yugoslavia). Of the 183 worldwide studies that met the selection criteria, 123 unique studies were conducted in Europe; all data extracted from the European incidence and prevalence studies, with the assessed quality scores, are presented in Additional file 3: Table S1 and Additional file 4: Table S2 respectively (listed chronologically by year of publication, within country). Even when stratified by region, heterogeneity among studies was found to be high $\left(\mathrm{I}^{2} \geq 84.4 \%, \mathrm{p}<0.0001\right)$ (see Figure 2). Given the disparity of the studies $\left(\mathrm{I}^{2}=\right.$

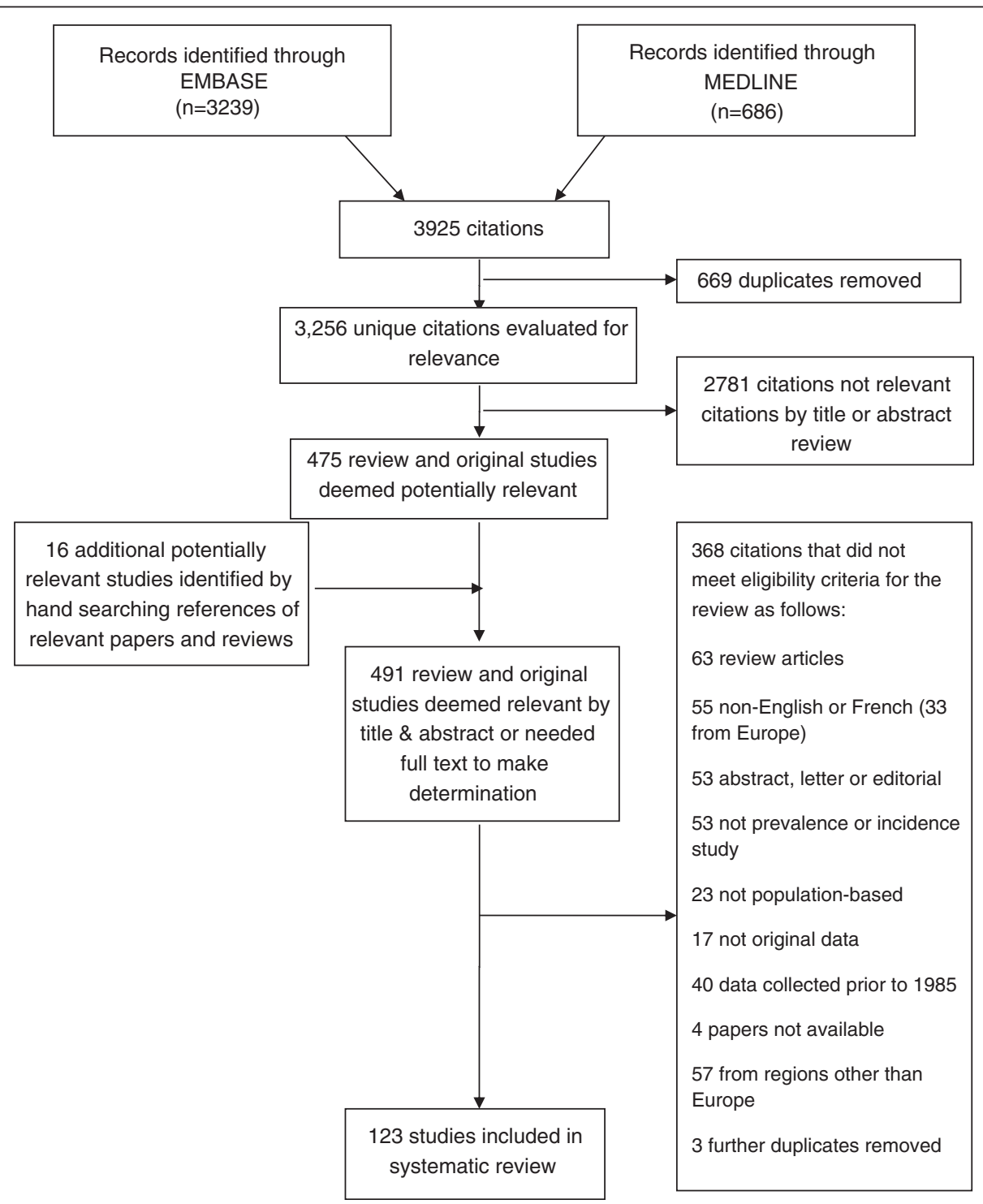

Figure 1 Flow diagram of selection of MS incidence and prevalence studies January 11985 - January 31, 2011. 


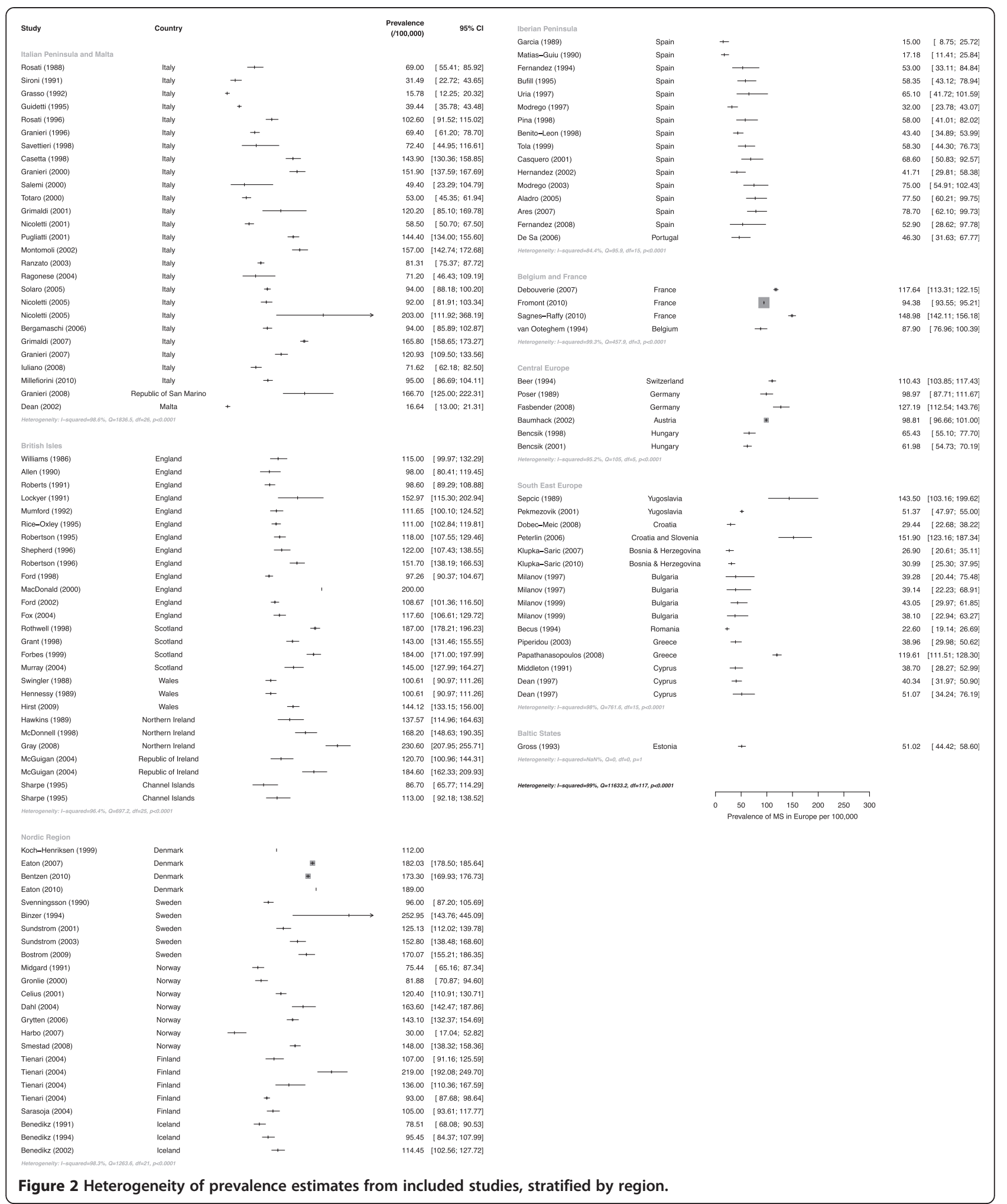

99\%, $\mathrm{Q}=11,633.2$, d.f. $=117, \mathrm{p}<0.0001$ ), a meta-analysis was not performed.

Prevalence estimates were more frequently reported than incidence estimates; 113 of the 123 studies reported prevalence estimates while 74 reported incidence estimates. Across Europe and over time, point prevalence estimates varied considerably. Estimates as low as $\leq 20 / 100,000$ were reported in some studies conducted in the 1980s [11-14], 
and also from more recent studies in Malta [15] and in ethnic minority populations of Norway and Bulgaria $[16,17]$. High estimates of $\geq 200 / 100,000$ were reported in parts of Scotland and Northern Ireland and also within specific populations in Scandinavia $[18,19]$ and Sicily [20]. Likewise, estimated annual incidence rates ranged widely from $<1 / 100,000[11,15]$ to $>10 / 100,000$ [20-22].

In the majority of studies the prevalence of MS was higher in women with sex ratios ranging from 1.1 to 3 . The average female to male prevalence ratio overall was approximately 2, ranging from 1.6 for South East Europe to 2.7 for studies from Central Europe; average prevalence ratios across Europe ranged between 1.6 to 2.8 in the $1980 \mathrm{~s}, 1.8$ to 2.5 in the $1990 \mathrm{~s}$ and 1.8 to 2.4 in the 2000s. Exceptions to the excess prevalence of women were noted in a small district of Northern Sweden (female to male ratio: 0.76$)$ where several of the identified cases were related [18], and among Turkish-speaking communities in Cyprus, (female to male ratio: 0.5) [23]. Relatively low female to male prevalence ratios (between 1 and 1.1) were seen in Greek-speaking communities in Cyprus [24], in Catania, Sicily (1989) [13] and in African and Asian ethnic populations in Norway [17]. However, when available, sex incidence ratios revealed generally higher rates for women that were in keeping with the overall higher female sex ratio for prevalence. As incidence ratios are not subject to survivor bias and are more etiologically relevant, their discussion is emphasized in favour of prevalence ratios in the description of the regional findings below.

In most of the reviewed studies cases were ascertained from a variety of sources including hospital and clinic records, neurologists and other physicians, patient associations and, in more recent years, from MS registries or administrative databases. Diagnosis was typically established through assessment by a health professional or review of medical records. MS cases were defined most frequently using the Poser criteria [25] (79\% of studies), although the inclusion or exclusion of 'probable' or 'possible' MS cases was not consistent across studies. The 2001 McDonald [26], Rose [27] and Schumacher [28] criteria were used in most of the remaining studies while the McAlpine [29] or McDonald/Halliday [30] criteria were used rarely.

Study quality scores varied from 1 to the maximum (7 or $8)$, and were somewhat lower for earlier studies compared to more recent reports. The mean quality score was 4.31 (standard deviation [SD]: 0.97) for studies conducted during or ending in the 1980s in contrast to 4.86 (SD: 1.02) for those conducted in the 1990s and 5.35 (SD: 1.08) after 2000. Lower quality scores were due to unclear reporting of standardized methods (78\% of the studies) or because confidence intervals were not included (25\% of the studies). Only $37 \%$ of the studies provided standardized estimates, although the diversity of standard populations chosen by the different studies hinders direct comparisons' of estimates. Nevertheless, estimates that are standardized to a large standard population are preferable to crude estimates and these adjusted estimates, when available, are presented in the following descriptive summaries.

\section{Italian Peninsula and Malta}

Italy has been particularly well-studied, although no single study evaluated the complete Italian mainland. Among the 28 reviewed studies from this region, nine were conducted in Sicily [13,20,31-37], seven in Northern Italy [38-44], seven in Sardinia [45-51], two in Central Italy [52,53], and one each in the south of Italy [54], San Marino [55] and Malta [15]. The Poser diagnostic criteria were used to identify cases in $25 / 28$ of the studies. Prevalence estimates ranged from a low of $15.8 / 100,000$ to a high of 197.8/ 100,000 , with the most extreme variation seen between the studies within Sicily [13,20]. Annual incidence estimates also varied widely across the region, ranging from 0.7 per 100,000 in the Maltese-born population of Malta [15] to $9.2 / 100,000$ in central Sicily [31]. A particularly high incidence estimate of 18.2 per 100,000 , for the small town of Linguaglossa, Sicily [20], is thought to represent a geographical and temporal cluster of cases.

It has been suggested that due to different genetic and environmental influences, Sardinia has a higher incidence and prevalence of MS compared to the rest of Italy [56]. Supporting this theory, five of the six studies of the Sardinian population have estimated the prevalence of MS at higher than 100/100,000 [45-47,49,51]. The only study with a lower estimate $(69 / 100,000)$ was carried out in 1985 [50]. However, when considering the incidence of MS, the Sardinian estimates $(3.4$ to $6.8 / 100,000)$ were not unlike those seen across the entire Italian peninsula.

Female to male ratios for MS incidence tended to be lower in Sicily; ranging from 1.19:1 to $1.84: 1$ [20,31-34,36] but were as high as 3:1 in San Marino [55] and Northwestern Sardinia [51]. The quality scores ranged between $3 / 7$ and $6 / 7$ with six of the studies from the Italian peninsula scoring $6 / 7[33,34,39,51,53]$. Ethnicity or race was considered in only one study from this region in which prevalence was reported separately for Maltese-born $(16.7 / 100,000)$ and foreign-born Maltese $(166 / 100,000)$ residents [15].

\section{The British Isles}

Together with the Italian peninsula, the British Isles was the most studied region with 28 unique prevalence or incidence studies. Of these, 13 were from England [57-69], six from Scotland [21,70-74], three from Wales [75-77], three from Northern Ireland [78-80], one from the Republic of Ireland [81], and one from the Channel Islands [82]. 
The remaining study estimated incidence of MS across the UK [83]. Allison and Millar criteria [3] were used, either alone or in combination with Poser criteria, in 12/28 studies from this region conducted between 1985 and 1996 [61,63-65,67,68,70,72,77,79,80,82].

Prevalence estimates in the British Isles ranged from $96 / 100,000$ in Guernsey [82] to more than 200/100,000, with the highest estimates originating from Scotland [21] and Northern Ireland [78]. These two countries also had the highest annual incidence rates (7.2 to 12.2 per 100,000) [21,78].

Sequential studies of either the same or overlapping populations in the South Glamorgan area of South Wales [75-77], North-Eastern Northern Ireland [78-80], and the Leeds health authority area in England [58,59] all demonstrated increasing prevalence and incidence. For example, in North-Eastern Northern Ireland the prevalence of MS increased from 138/100,000 in the mid-1980s [79] to $200.5 / 100,000$ in 2004 [78].

Annual incidence sex ratios ranged from 1.24:1 in North-Eastern Northern Ireland [78] to 2.82:1 in South-East Wales [76]. The quality scores for studies from the British Isles ranged from $2 / 7$ to $8 / 8$ with seven $(25 \%)$ of the 28 studies $[60,67,71,72,78,81,83]$ scoring 6 or higher. None of the studies from the British Isles reported prevalence or incidence by ethnic or racial subgroups.

\section{The Nordic region}

Twenty-five studies were reviewed from the Nordic region, including nine from Norway [17,84-91], five from Sweden [18,92-95], four from Denmark [96-99], three from Finland $[19,22,100]$, three from Iceland [101-103] and one from the Faroe Islands [104]. Most (19/25) of the studies used the Poser diagnostic criteria alone or in combination with other criteria. Four studies relied solely on McAlpine $[90,91,104]$ or Schumacher [18] criteria. Administrative International Classification of Diseases (ICD) codes were used to identify MS cases in two serial studies of the Danish National Hospital Register $[97,98]$.

The highest prevalence estimates in the Nordic region (over 200/100,000) were reported in Seinajoki-South, Finland [19] and in a small Northern rural district of Sweden (population denominator 4,744) [18]. Familial factors were suspected to play a role in the high number of cases found in both populations according to the study authors. The lowest prevalence estimates (20 - 30/ $100,000)$ in the Nordic countries were documented in Sami, Asian and African ethnic minority groups in Norway, well below the prevalence among 'Western' Norwegians $(170 / 100,000)$ during the same time period $[17,89]$. Prevalence estimates were $150 / 100,000$ or greater in the more recently conducted studies from Norway, Denmark and Sweden $[17,85,88,95-98]$.
Some of the highest annual incidence estimates in the Nordic countries (9.2 and 11.6/100,000) were found in specific central and Western regions of Finland [22,100]. A particularly low incidence was reported for the 19962000 time period in Iceland $(1.28 / 100,000)$ [103]. This may be an underestimate however as it was based on the incidence of MS symptom onset rather than year of diagnosis; additional cases with onset during this period may have been diagnosed after the findings were published in 2002. Annual incidence estimates in Iceland from the 1980s from the same study [103], as well as from a separate earlier study [101], both reported rates similar to that in other Nordic countries $(4.1-5.3 / 100,000)$.

For the 11 studies that reported sex specific incidence or incidence sex ratios, female to male annual incidence ratios ranged between 1.2 and 2.2 with no major regional or temporal differences. Quality scores ranged from $4 / 7$ to $8 / 8$, and seven (28\%) of the studies, including all Danish studies, scored $6 / 7$ or higher $[86,88,96-99,104]$. MS prevalence in ethnic minority groups was investigated in the two Norwegian studies described above $[17,89]$.

\section{Iberian Peninsula}

One study from central Portugal [105] and 15 from Spain were included in the review. The Spanish studies included 11 conducted on the mainland [14,106-115], three from the Canary Islands $[12,116,117]$ and one from the island of Menorca [118]. No studies incorporated the entire country of either Spain or Portugal.

The lowest prevalence estimates originated from the two earliest studies, conducted in the 1980s; from the island of Lanzarote in the Canary Islands $(15 / 100,000)$ [12] and from the city of Valencia, Spain $(17.7 / 100,0000)$ [14]. Prevalence increased over time with the highest estimates $(72$ and $77 / 100,000)$ observed in the most recent studies [106,112].

Ten studies from Spain studied annual incidence, reporting values ranging from 2.2 to 5.3/100,000 [14,106,107,111-113,115-118] with the highest estimates from studies concluded after 2000 [106,112,116].

Only two studies reported sex-specific incidence figures. The female to male ratio was 1.73:1 in Menorca [118] and 3.1:1 in Las Palmas City, Gran Canaria [116]. Quality scores ranged from 3/7 to 6/7 with three of the 15 studies (19\%) scoring 6/7 [105,107,112]. One study from this region estimated the prevalence of MS in the minority Roma population in Malaga, Southern Spain in 2002 as 52.9/100,000 [109], which was comparable to estimates in the non-Roma population in the same area in $1991(53 / 100,000)$ [110].

\section{Belgium and France}

One prevalence study originated from Belgium [119] and four incidence and/or prevalence studies were from France 
[120-123]. One French study utilized an administrative database to report national estimates [123].

Prevalence estimates ranged from 80-90/100,000, as observed in Flanders, Belgium [119] and in mostly Southern regions of France [123], up to 120-149/100,000 (2004) across regions of North-East France [123] and including one crude estimate from the Haute-Garonne region in South West France [122]. The overall prevalence of MS in France was estimated at 94.7/100,000 [123].

The lowest reported annual incidence in this region was from the city of Dijon in the mid-1990s (4.3/ 100,000) [121]. Figures a decade later were higher; 7.5/ 100,000 for the whole country with regional estimates ranging from 6.1 to 10.8 [123].

Annual incidence sex ratios across France in 2004 demonstrated considerable variation; ranging from 1.4/ 100,000 in Corsica to $4.1 / 100,000$ in central France [123]. The quality scores for these studies varied between $5 / 7$ and $7 / 8$ with two of the studies (40\%) scoring $7 / 8$ $[122,123]$. No studies examined ethnic sub-groups in either Belgium or France.

\section{Central European countries}

Six studies from Central Europe met selection criteria; one from Switzerland [124], two from Germany [125,126], one from Austria [127] and two from Hungary [128,129]. Crude prevalence estimates from this region ranged from $62 / 100,000$ to $128 / 100,000$. The lowest estimates originated from Hungary in the 1990s [128,129] and from Germany in 1986 [125] while the highest estimate, also from Germany, was found in the most recent study (2006) [126]. Annual incidence was estimated in the studies from Hungary and Germany to range between 6/100,000 and 7.7/100,000 without any clear temporal differences $[125,126,128,129]$.

Two studies provided female to male incidence ratios; a ratio of 3:1 was reported in Germany in 2006 [126] while an earlier study from Hungary completed in 1996 reported a ratio of 1.5:1 [129]. Quality scores in the Central European studies ranged from $1 / 7$ to $6 / 7$ with only one study (17\%) scoring 6/7 [126]. No studies from this region reported prevalence or incidence by ethnic or racial subgroups.

\section{South East Europe}

Fourteen of the studies included in this review were from South East Europe, covering the former Yugoslavia [130,131], Croatia [132-134], Slovenia [134], Bosnia and Herzegovina [135,136], Bulgaria [16,137], Romania [11], Greece [138,139], and Greek- and Turkish-speaking communities in Cyprus [23,24].

Most of the prevalence estimates in South East Europe fell between a lower value of approximately 20/100,000, as recorded in Romania [11] and in both rural and urban
Roma populations in Bulgaria [16], and an upper value of approximately 50/100,000 in other regional studies [23,24,131,133,135-137,139]. However, higher prevalence estimates (144 and 152/100,000), were documented in the Gorski Kotar region of North-West Croatia [130,134] and in the neighboring region (the municipalities of Kocevje and Ribnica) in South East Slovenia [134]. The one-year incidence estimate for 1986 was also moderately high $(3.78 / 100,000)$ in these two regions, prompting suspicion that a strong familial influence is at play in this isolated population [130]. A study in western Greece also reported high prevalence $(120 / 100,000)$ and incidence $(9.5 / 100,000)$ estimates [138], that were notably higher than those of a study conducted seven years earlier in the northeastern region of Evros (prevalence of 38.9/100,000 and annual incidence of 2.36/100,000) [139]; possibly explained by increased awareness, knowledge and availability of MRI machines [138]. Among the remaining four studies that measured annual incidence of MS, estimates ranged from $0.32 / 100,000$ in Romania [11] and $0.8 / 100,000$ in Croatia [132] to 1.1 or $1.6 / 100,000$ in recent studies from Bosnia and Herzegovina $[135,136]$.

One incidence study provided sex-specific data and reported a female to male ratio of 1.69:1 in Western Greece [138]. Quality scores in South East Europe range from $2 / 8$ to $6 / 7$; only the two studies from Greece $[138,139]$ scoring $6 / 7$. Ethnic differences were highlighted by a 1998 report of MS prevalence among the Roma and non-Roma population in two regions of Bulgaria. The prevalence in the Roma $(19 / 100,000)$ was found to be half that of the non-Roma $(45 / 100,000)$ population in both regions [16].

\section{The Baltic states}

Only one study from the Baltic States, a prevalence study in Southern Estonia in 1989, was included [140]. Schumacher criteria were used to identify cases, and the estimated prevalence in the entire population was 50/ 100,000 . The quality score for this study was $4 / 7$. The prevalence of MS in native Estonians was 55/100,000 in contrast to 29/100,000 among those of Russian descent, including those born in Estonia and first-generation Russian immigrants.

\section{Discussion}

This systematic review has comprehensively catalogued the incidence and prevalence of MS across Europe between January 1985 and January 2011, and unlike prior systematic reviews [141-143] of this region, has summarized methodologies and evaluated study quality using an objective measure and a predetermined set of criteria. We aimed to describe potential temporal and demographic patterns that could be appreciated at the continental 
level and to identify gaps in the literature, including regions or populations that are under-represented.

Some European regions have undergone several MS incidence or prevalence studies over this 27 year period; more than 25 studies originated from each of the British Isles, Italy, and the Nordic region. Spain has also been well represented. Variability in representation within individual countries was marked; of the 28 Italian studies, for example, 16 were performed in either Sardinia or Sicily, and only 12 on the mainland where most of the Italian population lives. There is a relative paucity of studies from Central and Eastern Europe and the 11 Sicilian studies equal the total number of studies undertaken in all of France, Belgium, Germany, Switzerland, Austria and Hungary combined.

While much of the literature has focused on specific regions or individual cities within a given country, a few studies reported countrywide data $[15,55,83,96-99,101$, 103,123,127]. The extensive population of many European countries limits the capacity to ascertain MS cases at the national level. Administrative databases offer the means to estimate the burden of MS at this level, but comparability between studies has been limited due to the various case definitions that have been used. These have included the granting of permanent disability status with MS or the need for disease modifying therapy [123], the presence of an incident International Classification of Disease code (ICD) for MS $[97,98]$, and the more typical neurologist confirmed diagnosis by standard criteria [83,96]. As validated case definitions for MS in administrative data are now available $[144,145]$, there is the potential for greater comparability between estimates derived from these sources in the future.

Ethnic differences were presented in very few reports. Two Norwegian studies assessed MS rates in Asian and African minority groups, or in the indigenous Sami, separately from the remainder of the Norwegian population $[17,89]$, and found up to an eight-fold lower prevalence in those groups. Non-Maltese born residents (mostly originating from Northern Europe) had a 10-times higher prevalence than Maltese-born individuals [15]. Single studies from Spain [109] and Bulgaria [16] revealed that prevalence was lower in the Roma compared to non-Roma populations from the same regions. Lastly, the Estonian report [140] examined Estonian- and Russian-born populations separately and found a lower prevalence in those originating from Russia. Studies such as these provide unique and valuable information, and can potentially be used to differentiate the role of genetic and environmental factors in MS.

Prevalence and incidence estimates tended to be higher in the Northern regions of the United Kingdom and in the Nordic Countries, implicating the role of latitude. This pattern is not uniform however, with higher estimates originating as far south as Sicily and Greece [20,31,138]. Although there were some rare reports of lower prevalence ratios of women to men [18,23], the incidence sex ratios (when available) revealed consistently higher rates of women than men with MS across Europe with no obvious patterns between north and south. The issues of latitude-dependent gradients in MS incidence, prevalence, and sex ratios, have been addressed in detail by recent reviews $[4,146]$.

The assessed quality of these epidemiological studies varied both geographically and temporally. The more recent literature had higher quality scores in general, with the mean scores increasing from 4.31 for studies with data collection before 1990, to 5.35 in those conducted since 2000. The studies from France and Belgium scored high on average; however, these were also among the most recent. Those originating from the British Isles were methodologically weaker overall but included a greater proportion of earlier studies. When comparing estimates between regions it is important to recognize the inter-related issues of the methodological quality of the study, the size of the source population, the time period over which the study was performed and the diagnostic criteria that were used. For example, the Poser criteria were the most widely used (either alone or combined with other criteria in 100 of the 123 studies), although studies varied regarding inclusion of "probable" and "possible" cases. However, many of the earlier studies from the British Isles relied on the Allison-Millar or Rose criteria; older criteria that may be more inclusive and thereby might inflate prevalence or incidence estimates $[69,72]$. However, any such effect depends on whether cases in Allison-Millar's "possible" or "early" categories are included $[72,77,80]$. The definition of incidence also varied, with most studies reporting incidence based on the date of diagnosis, but others using the date of MS symptom onset $[15,39,40,42,46,55,70,87,101,103,117,118]$. This latter definition can sometimes result in an apparent decrease in incidence rates during the most recent time period [103] due to the time-lag between onset and diagnosis [147-149].

The more recent studies reported higher MS prevalence or incidence estimates. Prevalence estimates would be expected to increase over time if life expectancy of those with MS increases; incidence is therefore considered a better indicator of changes in disease rates [4]. However, given the differences in study methodology and quality as described above, it is difficult to determine if the observed changes in incidence estimates over time are due to real changes in the risk of MS. Additional factors which can be related to an earlier diagnosis, including access to neurological care and disease modifying therapies as well as the availability of MRI, have also changed over 
time. Comparisons are further limited by the lack of appropriate standardization; only $42 \%$ of the prevalence studies and $22 \%$ of the incidence studies included ageand sex-standardized estimates, and among these, a variety of standard populations were used. The effects of several of these limitations have previously been highlighted and recommendations have been made that would allow for reliable comparisons between MS epidemiological studies $[142,143,150]$.

This review has some limitations. Once the data abstraction of the 123 unique studies from Europe was complete, considerable inter-study variability was evident, preventing a meaningful quantitative synthesis of the data even within regions or countries. The included studies are limited to publications in English or French and, although few studies identified in the initial review were excluded dues to language, their exclusion is likely to have biased data collection in favour of Western European countries. Of the 33 articles excluded for language, 13 originated from countries not represented in this review; i.e. Russia, the Ukraine, Poland and the Czech Republic or Slovakia. The grouping of countries into eight European regions was predominantly based on geography for descriptive purposes, and these groupings may not be appropriate for all questions related to the distribution of MS within Europe. Strengths of the study included the comprehensive assessment of study quality, and the independent data abstraction by two reviewers with subsequent verification by the first author and the comprehensive assessment of study quality. This quality scoring system not only offers a grading system for existing literature but a guide to improving the design of future MS incidence and prevalence studies.

\section{Conclusion}

While there was marked variability in the methodological quality of the studies reviewed, we can report that methods seem to have improved over time, as demonstrated by the trend towards higher quality scores in later studies. Most prevalence and incidence estimates are derived from towns or regions within a country, but national studies have become increasingly feasible with the availability of large databases and registries. The use of such resources may improve comparability between estimates, although attention should be paid to the validity and comparability of case definitions. Spatial and temporal comparisons would be facilitated if studies were to adopt a universal standard population, and if age- and sex-specific estimates were uniformly provided. The prevalence and incidence of MS are not well documented in many regions of Europe. As incidence and prevalence of MS vary considerably between different ethnic populations, greater attention should also be paid to the ethnic composition of source populations and cases.

\section{Additional files}

\section{Additional file 1: Multiple sclerosis search strategy EMBASE \& MEDLINE. Details of search strategy to retrieve abstracts.}

Additional file 2: Quality assessment form. Questionnaire completed by two independent reviewers for each study.

Additional file 3: Table S1. Incidence of multiple sclerosis, Europe, January 1 1985-January 31, 2011.

Additional file 4: Table S2. Prevalence of multiple sclerosis, Europe, January 1 1985-January 31, 2011.

\section{Abbreviations}

ICD: International classification of diseases; MS: Multiple sclerosis; SD: Standard deviation.

\section{Competing interests}

The authors declare that they have no competing interests.

\section{Authors' contributions}

EK and JJM participated in the data abstraction, reviewed and verified all abstracted data, drafted and revised the manuscript. NJ and TP conceived of the study and participated in its design and coordination. NM, SM, JF, CE and MWK participated in the data abstraction. SGB and JD participated in the study design and coordination. SK and CW participated in the study design and coordination and reviewed each abstract. RAM conceived of the study, participated in its design and coordination and reviewed each abstract. All authors read and approved the final manuscript.

\section{Acknowledgements}

Thanks to Ms. Diane Lorenzetti, Librarian at University of Calgary who developed the search strategies and to Ms. Ingrid Dixon at the McGill Life Sciences Library who obtained copies of papers that were not available online. Thanks to Dr. Parminder Raina and Ms. Mary Gauld, at the Evidence Review and Synthesis Centre of McMaster University for kindly hosting us on the DistillerSR system and thanks to Mr. Henry Ebron and Mr. lan Stefanison from DistillerSR for patiently guiding us through the conduct of a first project on the DistillerSR system. This study is part of the National Population Health Study of Neurological Conditions. We wish to acknowledge the membership of Neurological Health Charities Canada and the Public Health Agency of Canada for their contribution to the success of this initiative.

\section{Funding}

Funding for this study was provided by the Public Health Agency of Canada. Elaine Kingwell was funded by a Michael Smith Foundation for Health Research Postdoctoral Fellowship and received funding from the Multiple Sclerosis Society of Canada (Postdoctoral Fellowship). Nathalie Jette holds an Alberta Innovates Health Solutions Population Health Investigator Award and a Canada Research Chair Tier 2 in Neurological Health Services Research. Ruth Ann Marrie receives funding from a Don Paty Career Development Award (Multiple Sclerosis Society of Canada). The opinions expressed in this publication are those of the authors/researchers, and do not necessarily reflect the official views of the Public Health Agency of Canada.

\section{Author details}

${ }^{1}$ Division of Neurology, Faculty of Medicine, University of British Columbia, Vancouver, Canada. ${ }^{2}$ Department of Internal Medicine, University of Manitoba, Winnipeg, Canada. ${ }^{3}$ Department of Community Health Sciences, University of Calgary, Calgary, Canada. ${ }^{4}$ Department of Clinical Neurosciences and Hotchkiss Brain Institute, University of Calgary, Calgary, Canada. ${ }^{5}$ Institute for Public Health, University of Calgary, Calgary, Canada. ${ }^{6}$ Department of Pediatrics, University of Calgary, Calgary, Canada. ${ }^{7}$ Division of Neurology and Department of Pediatrics, University of Toronto, Toronto, Canada.

${ }^{8}$ Department of Clinical Neurological Sciences, University of Western Ontario, London, Canada. ${ }^{9}$ Departments of Psychiatry and Medicine, Dalhousie University, Halifax, Canada. ${ }^{10}$ College of Pharmacy and Nutrition, University of Saskatchewan, Saskatoon, Canada. ${ }^{11}$ Research Institute of the McGill University Health Centre, McGill University, Montreal, Canada. ${ }^{12}$ Department 
of Epidemiology \& Biostatistics and Occupational Health, McGill University, Montreal, Canada.

Received: 27 May 2013 Accepted: 17 September 2013 Published: 26 September 2013

\section{References}

1. World Health Organization: Atlas multiple sclerosis resources in the world 2008. Geneva: WHO Press; 2008

2. Poser $C M$, Brinar $W$ : The accuracy of prevalence rates of multiple sclerosis: a critical review. Neuroepidemiology 2007, 29(3-4):150-155.

3. Ebers GC: Environmental factors and multiple sclerosis. The Lancet Neurology 2008, 7(3):268-277.

4. Koch-Henriksen N, Sørensen PS: The changing demographic pattern of multiple sclerosis epidemiology. Lancet Neurol 2010, 9:520-532.

5. Alonso A, Hernan MA: Temporal trends in the incidence of multiple sclerosis: a systematic review. Neurology 2008, 71(2):129-135.

6. Orton S-M, Herrera BM, Yee IM, Valdar W, Ramagopalan SV, Sadovnick AD, Ebers GC: Sex ratio of multiple sclerosis in Canada: a longitudinal study. Lancet Neurol 2006, 5:932-936.

7. Ramagopalan SV, Byrnes JK, Orton SM, Dyment DA, Guimond C, Yee IM, Ebers GC, Sadovnick AD: Sex ratio of multiple sclerosis and clinical phenotype. Eur J Neurol 2010, 17(4):634-637.

8. Trojano M, Lucchese G, Graziano G, Taylor BV, Simpson SJ, Lepore V, Grand'maison F, Duquette P, Izquierdo G, Grammond P, et al: Geographical variations in sex ratio trends over time in multiple sclerosis. PLOS One 2012, 7(10):348078

9. Kurtzke JF: Multiple sclerosis in time and space-geographic clues to cause. J Neurovirol 2000, 6(Suppl 2):S134-S140.

10. Evans C, Beland SG, Kulaga S, Wolfson C, Kingwell E, Marriott J, Koch M, Makhani N, Morrow S, Fisk J, et al: Incidence and Prevalence of Multiple Sclerosis in the Americas: a systematic review. Neuroepidemiology 2013, 40(3):195-210.

11. Becuș T, Popoviciu L: Epidemiologic survey of multiple sclerosis in Mureș County, Romania. Rom J Neurol Psychiat 1994, 32(2):115-122.

12. Garcia JR, Rodriguez S, Sosa Henriquez M, Batista E, Corujo E, Font De Mora Turon A, Hernandez Hernandez D, Betancor Leon P: Prevalence of multiple sclerosis in Lanzarote (Canary Islands). Neurology 1989, 39:265-267.

13. Grasso AA, Regio A, Marano P, Florio S, Scordino N, Cappello S, Nicoletti F: Epidemiological survey of multiple sclerosis in Catania city. Ital I Neurol Sci 1992, 13:301-309.

14. Matias-Guiu J, Bolumar F, Martin R, Insa R, Casquero P, Moltó JM, Calatayud EJA: Multiple sclerosis in Spain: an epidemiological study of the Alcoy health region, Valencia. Acta Neurol Scand 1990, 6:479-493.

15. Dean G, Elian M, Galea De Bono A, Pace Asciak R, Vella N, Mifsud V, Aquilina J: Multiple sclerosis in Malta in 1999: an update. J Neurol Neurosurg Psychiatry 2002, 73:256-260.

16. Milanov I, Topalov N, Kmetska T: Prevalence of Multiple Sclerosis in Gypsies and Bulgarians. Neuroepidemiology 1999, 18:218-222.

17. Smestad C, Sandvik L, Holmoy T, Harbo HF, Celius EG: Marked differences in prevalence of multiple sclerosis between ethnic groups in Oslo, Norway. J Neurol 2008, 255(1):49-55.

18. Binzer M, Forsgren $L$, Holmgren $G$, Drugge $U$, Fredrikson S: Familial clustering of multiple sclerosis in a northern Swedish rural district. J Neurol Neurosurg Psychiatry 1994, 57:497-499.

19. Tienari PJ, Sumelahti ML, Rantamaki T, Wikstrom J: Multiple sclerosis in western Finland: evidence for a founder effect. Clin neurol neurosur 2004 106(3):175-179.

20. Nicoletti A, Lo Fermo S, Reggio E, Tarantello R, Liberto A, Le Pira F, Patti F, Reggio A: A possible spatial and temporal cluster of multiple sclerosis in the town of Linguaglossa, Sicily. J Neurol 2005, 252(8):921-925.

21. Rothwell PM, Charlton D: High incidence and prevalence of multiple sclerosis in south east Scotland: evidence of a genetic predisposition. J Neurol Neurosurg Psychiatry 1998, 64:730-735.

22. Sumelahti ML, Tienari PJ, Wikström J, Palo J, Hakama M: Regional and Temporal Variation in the Incidence of Multiple Sclerosis in Finland 1979-1993. Neuroepidemiology 2000, 19:67-75.

23. Dean $G$, Aksoy $H$, Akalin T, Middleton L, Kyriallis $K$ : Multiple sclerosis in the Turkish- and Greek-speaking communities of Cyprus: a United Nations (UNHCR) Bicommunal Project. J Neurol Sci 1997, 145:163-168.

24. Middleton L, Dean G: Multiple sclerosis in Cyprus. J Neurol Sci 1991, 103:29-36.
25. Poser CM, Paty DW, Scheinberg L, McDonald WI, Davis FA, Ebers GC Johnson KP, Sibley WA, Silberberg DH, Tourtellotte WW: New diagnostic criteria for multiple sclerosis: guidelines for research protocols. Ann Neurol 1983, 13(3):227-231.

26. McDonald WI, Compston A, Edan G, Goodkin D, Hartung HP, Lublin FD, McFarland HF, Paty DW, Polman CH, Reingold SC, et al: Recommended diagnostic criteria for multiple sclerosis: guidelines from the International Panel on the Diagnosis of Multiple Sclerosis. Ann Neurol 2001, 50:121-127.

27. Rose AS, Ellison GW, Myers LW, Tourtellotte WW: Criteria for the clinical diagnosis of multiple sclerosis. Neurology 1976, 26:20-22.

28. Schumaker GA, Beebe G, Kibler RF, Kurland LT, Kurtzke JF, McDowell F, Nagler B, Sibley WA, Tourtellotte WW, Willmon TL: Problems of experimental trials of therapy in multiple sclerosis. Ann NY Acad Sci 1965, 122:552-568.

29. McAlpine D, Lumsden CE, Acheson ED: Multiple sclerosis: a reappraisal. Edinburgh: Churchill Livingstone; 1972.

30. McDonald WI, Halliday AM: Diagnosis and classification of multiple sclerosis. Br Med Bull 1977, 33:4-9.

31. Grimaldi LM, Palmeri B, Salemi G, Giglia G, D'Amelio M, Grimaldi R, Vitello G, Ragonese $P$, Savettieri G: High prevalence and fast rising incidence of multiple sclerosis in Caltanissetta, Sicily, southern Italy. Neuroepidemiology 2007, 28(1):28-32.

32. Grimaldi LME, Salemi G, Grimaldi G, Rizzo A, Marziolo R, Lo Presti C, Maimone D, Savettieri G: High incidence and increasing prevalence of MS in Enna (Sicily), southern Italy. Neurology 2001, 57:1891-1893.

33. Nicoletti A, Lo Bartolo ML, Lo Fermo S, Cocuzza V, Panetta MR, Marletta C, Ciancio MR, Cataldi ML, Patti F, Reggio A: Prevalence and incidence of multiple sclerosis in Catania, Sicily. Neurology 2001, 56:62-66.

34. Nicoletti A, Patti F, Lo Fermo S, Sorbello V, Reggio E, Maimone D, Zappia M, Reggio A: Possible increasing risk of multiple sclerosis in Catania, Sicily. Neurology 2005, 65:1259-1263.

35. Ragonese P, Salemi G, D'Amelio M, Gammino M, Aridon P, Savettieri G Multiple sclerosis in southern Europe: Monreale City, Italy. A twenty-year follow-up incidence and prevalence study. Neuroepidemiology 2004, 23(6):306-309

36. Salemi G, Ragonese P, Aridon P, Scola G, Saporito V, Conte S, Savettieri G: Incidence of multiple sclerosis in Bagheria City, Sicily, Italy. Neurol Sci 2000, 21:361-365.

37. Savettieri G, Salemi G, Ragonese P, Aridon P, Scola G, Randisi G: Prevalence and incidence of multiple sclerosis in the city of Monreale, Italy. J Neurol 1998, 245:40-43.

38. Bergamaschi R, Montomoli C, Candeloro E, Monti MC, Cioccale R, Bernardinelli L, Fratino P, Cosi V, Group P: Bayesian mapping of multiple sclerosis prevalence in the province of Pavia, northern Italy. J Neurol SCi 2006, 244(1-2):127-131.

39. Granieri E, Economou NT, De Gennaro R, Tola MR, Caniatti L, Govoni V, Fainardi E, Casetta I: Multiple sclerosis in the province of Ferrara: evidence for an increasing trend. J Neurol 2007, 254(12):1642-1648.

40. Granieri E, Malagu S, Casetta I, Tola MR, Govoni V, Paolino E, Monetti VC Multiple sclerosis in Italy: a reappraisal of incidence and prevalence in Ferrara. Arch Neurol 1996, 53:793-798.

41. Guidetti D, Cavalletti S, Merelli E, Zanoni P, Simonazzi P, Sola P, Solime F: Epidemiological survey of multiple sclerosis in the provinces of Reggio Emilia and Modena, Italy. Neuroepidemiology 1995, 14:7-13.

42. Ranzato F, Perini P, Tzintzeva E, Tiberio M, Calabrese M, Ermani M, Davetag $F$, De L, Garbin E, Verdelli F, et al: Increasing frequency of multiple sclerosis in Padova, Italy: a 30 year epidemiological survey. Multiple sclerosis 2003, 9(4):387-392.

43. Sironi L, Mamoli A, D'Alessandro G, Camerlingo M, Bottacchi E: Frequency of multiple sclerosis in Valle d'Aosta, 1971-1985. Neuroepidemiology 1991, 10:66-69.

44. Solaro C, Allemani C, Messmer Uccelli M, Canevari E, Dagnino N, Pizio R, Regesta G, Tanganelli P, Battaglia MA, Mancardi GL: The prevalence of multiple sclerosis in the north-west Italian province of Genoa. J Neurol 2005, 252(4):436-440.

45. Casetta I, Granieri E, Marchi D, Murgia SB, Tola MR, Ticca A, Lauria G, Govoni V, Murgia B, Pugliatti M: An epidemiological study of multiple sclerosis in central Sardinia, Italy. Acta Neurol Scand 1998, 98:391-394.

46. Granieri E, Casetta I, Govoni V, Tola MR, Marchi D, Murgia SB, Ticca A, Pugliatti M, Murgia B, Rosati G: The increasing incidence and prevalence of MS in a Sardinian province. Neurology 2000, 55:842-847. 
47. Montomolia C, Allemania C, Solinasa G, Mottaa G, Bernardinellia L, Clementeb S, Murgiac BS, Ticcac AF, Musuc L, Pirasc ML, et al: An ecologic study of geographical variation in multiple sclerosis risk in central Sardinia, Italy. Neuroepidemiology 2002, 21:187-193.

48. Pugliatti M, Riise T, Sotgiu MA, Sotgiu S, Satta WM, Mannu L, Sanna G, Rosati $\mathrm{G}$ : Increasing incidence of multiple sclerosis in the province of Sassari, northern Sardinia. Neuroepidemiology 2005, 25(3):129-134.

49. Pugliatti M, Sotgiu S, Solinas G, Castiglia P, Pirastru M, Murgia B, Mannu L, Sanna G, Rosati G: Multiple sclerosis epidemiology in Sardinia: evidence for a true increasing risk. Acta Neurol Scand 2001, 103:20-26.

50. Rosati G, Aiello I, Mannu L, Pirastru MI, Agnetti V, Sau G, Garau M, Gioia R, Sanna G: Incidence of multiple sclerosis in the town of Sassari, Sardinia, 1965 to 1985: evidence for increasing occurrence of the disease. Neurology 1988, 38:384-388.

51. Rosati G, Aiello I, Pirastru MI, Mannu L, Sanna G, Sau GF, Sotgiu S: Epidemiology of multiple sclerosis in northwestern Sardinia: further evidence for higher frequency in Sardinians compared to other Italians. Neuroepidemiology 1996, 15:10-19.

52. Millefiorini E, Cortese A, Di Rezze S, Barletta G, Bellantonio P, Batocchi AP, Di Battista G, Fiore S, Gasperini C, Grasso MG, et al: The prevalence of multiple sclerosis in central Italy. Multiple sclerosis 2010, 16(12):1432-1436.

53. Totaro R, Marini C, Cialfi A, Giunta M, Carolei A: Prevalence of multiple sclerosis in the L'Aquila district, central Italy. J Neurol Neurosurg Psychiatry 2000, 68:349-352.

54. Iuliano G, Napoletano R: Prevalence and incidence of multiple sclerosis in Salerno (southern Italy) and its province. Eur J Neurol 2008, 15(1):73-76.

55. Granieri E, Monaldini C, De Gennaro R, Guttmann S, Volpini M, Stumpo M, Fazio P, Casetta I: Multiple sclerosis in the Republic of San Marino: a prevalence and incidence study. Multiple sclerosis 2008, 14(3):325-329.

56. Sotgiu S, Pugliatti M, Sanna A, Sotgiu A, Castiglia P, Solinas G, Dolei A, Serra C, Bonetti B, Rosati G: Multiple sclerosis complexity in selected populations: the challenge of Sardinia, insular Italy. Eur J Neurol 2002, 9:329-341.

57. Allen KW: The prevalence of multiple sclerosis in the health district of Bassetlaw. Public Heal 1990, 104:37-43.

58. Ford HL, Gerry E, Airey CM, Vail A, Johnson MH, Williams DRR: The prevalence of multiple sclerosis in the Leeds Health Authority. J Neurol Neurosurg Psychiatry 1998, 64:605-610

59. Ford $H L$, Gerry $E$, Johnson M, Williams R: A prospective study of the incidence, prevalence and mortality of multiple sclerosis in Leeds. J Neurol 2002, 249:260-265.

60. Fox CM, Bensa S, Bray I, Zajicek JP: The epidemiology of multiple sclerosis in Devon: a comparison of the new and old classification criteria. J Neurol Neurosurg Psychiatry 2004, 75:56-60.

61. Lockyer MJ: Prevalence of multiple sclerosis in five rural Suffolk practices. BMJ 1991, 303:347-348.

62. MacDonald BK, Cockerell OC, Sander JWAS, Shorvon SD: The incidence and lifetime prevalence of neurological disorders in a prospective community-based study in the UK. Brain 2000, 123:665-676.

63. Mumford CJ, Fraser MB, Wood NW, Compston DAS: Multiple sclerosis in the Cambridge health district of East Anglia. J Neurol Neurosurg Psychiatry 1992, 55:877-882.

64. Roberts MHW, Martin JP, McLellan DL, Mclntosh-Michaelis SA, Spackman AJ: The prevalence of multiple sclerosis in the Southampton and South West Hampshire Health Authority. J Neurol Neurosurg Psychiatry 1991, 54:55-59.

65. Robertson N, Deans J, Fraser M, Compston DAS: Multiple sclerosis in the north Cambridgeshire districts of East Anglia. J Neurol Neurosurg Psychiatry 1995, 59:71-76.

66. Robertson N, Deans J, Fraser M, Compston DAS: Multiple sclerosis in south Cambridgeshire: incidence and prevalence based on a district register. J Epidemiol Community Health 1996, 50:274-279.

67. Shepherd DI, Summers A: Prevalence of multiple sclerosis in Rochdale. J Neurol Neurosurg Psychiatry 1996, 61:415-417.

68. Williams ES, McKeran RO: Prevalence Of Multiple Sclerosis In A South London Borough. BMJ 1986, 293(6541):237-239.

69. Rice-Oxley M, Williams ES, Rees JE: A prevalence survey of multiples clerosis in Sussex. J Neurol Neurosurg Psychiatry 1995, 58:27-30.

70. Cook SD, MacDonald J, Tapp W, Poskanzer D, Dowling PC: Multiple sclerosis in the Shetland Islands: an update. Acta Neurol Scand 1988, 77:148-151.

71. Donnan PT, Parratt JDE, Wilson SV, Forbes RB, O'Riordan JI, Swingler RJ: Multiple sclerosis in Tayside, Scotland: detection of clusters using a spatial scan statistic. Multiple sclerosis 2005, 11(4):403-408.
72. Forbes RB, Wilson SV, Swingler RJ: The prevalence of multiple sclerosis in Tayside, Scotland: do latitudinal gradients really exist? J Neurol 1999, 246:1033-1040.

73. Grant RM, Carver AD, Sloan RL: Multiple sclerosis in Fife. Scot Med J 1998 42:44-47.

74. Murray S, Bashir K, Penrise G, Womersley SJ: Epidemiology of multiple sclerosis in Glasgow. Scot Med J 2004, 49:100-104.

75. Hennessy A, Swingler RJ, Compston DAS: The incidence and mortality of multiple sclerosis in southeast Wales. J Neurol Neurosurg Psychiatry 1989, 52:1085-1089.

76. Hirst C, Ingram G, Pickersgill T, Swingler R, Compston DA, Robertson NP: Increasing prevalence and incidence of multiple sclerosis in South East Wales. J Neurol Neurosurg Psychiatry 2009, 80(4):386-391.

77. Swingler RJ, Compston DAS: The prevalence of multiple sclerosis in South East Wales. J Neurol Neurosurg Psychiatry 1988, 51:1520-1524.

78. Gray OM, McDonnell GV, Hawkins SA: Factors in the rising prevalence of multiple sclerosis in the north-east of Ireland. Multiple sclerosis 2008 14(7):880-886

79. Hawkins SA, Kee K: The changing prevalence of multiple sclerosis in Northern Ireland with reference to benign multiple sclerosis. In Recent advances in multiple sclerosis therapy: proceedings of the Vth Congress of the European Committee for Treatment and Research in Multiple Sclerosis (ECTRIMS), Brussels, 16-18 March 1989. Edited by Gonsette RE, Delmotte P. Amsterdam: Excerpta Medica; 1989:357-358.

80. McDonnell GV, Hawkins SA: An epidemiologic study of multiple sclerosis in Northern Ireland. Neurology 1998, 50:423-428.

81. McGuigan C: Latitudinal variation in the prevalence of multiple sclerosis in Ireland, an effect of genetic diversity. J Neurol Neurosurg Psychiatry 2004, 75(4):572-576.

82. Sharpe G, Price SE, Last A, Thompson RJ: Multiple sclerosis in island populations: prevalence in the Bailiwicks of Guernsey and Jersey. J Neurol Neurosurg Psychiatry 1995, 58:22-26.

83. Alonso A, Jick SS, Olek MJ, Hernan MA: Incidence of multiple sclerosis in the United Kingdom : findings from a population-based cohort. J Neurol 2007, 254(12):1736-1741.

84. Celius EG, Vandvik B: Multiple sclerosis in Oslo, Norway: prevalence on 1 January 1995 and incidence over a 25-year period. Eur J Neurol 2001, 8:463-469.

85. Dahl OP, Aarseth JH, Myhr KM, Nyland H, Midgard R: Multiple sclerosis in Nord-Trøndelag County, Norway: a prevalence and incidence study. Acta Neurol Scand 2003, 109:378-384.

86. Grønlie SA, Myrvoll E, Hansen G, Grønning M, Mellgren SI: Multiple sclerosis in North Norway, and first appearance in an indigenous population. J Neurol 2000, 247:129-133.

87. Grønning M, Riise T, Kvåle G, Nyland H, Larsen JP, Aarli JA: Incidence of multiple sclerosis in Hordaland, western Norway: a fluctuating pattern. Neuroepidemiology 1991, 10:53-61.

88. Grytten N, Glad SB, Aarseth JH, Nyland H, Midgard R, Myhr K-M: A 50-year follow-up of the incidence of multiple sclerosis in Hordaland County, Norway. Neurology 2006, 66:182-186.

89. Harbo HF, Utsi E, Lorentzen AR, Kampman MT, Celius EG, Myhr KM, Lie BA, Mellgren SI, Thorsby E: Low frequency of the disease-associated DRB1*15DQB1*06 haplotype may contribute to the low prevalence of multiple sclerosis in Sami. Tissue antigens 2007, 69(4):299-304.

90. Midgard R, Riise T, Nyland H: Epidemiologic trends in multiple sclerosis in Møre and Romsdal, Norway: a prevalence/incidence study in a stable population. Neurology 1991, 41:887-892

91. Midgard R, Riise T, Svanes C, Kvåle G, Nyland H: Incidence of multiple sclerosis in MOre and Romsdal, Norway from 1950 to 1991: an ageperiod-cohort analysis. Brain 1996, 119:203-211.

92. Sundström $P$, Nyström L, Forsgren L: Prevalence of multiple sclerosis in Västerbotten County in northern Sweden. Acta Neurol Scand 2001, 103:214-218.

93. Sundström P, Nyström L, Forsgren L: Incidence (1988-97) and prevalence (1997) of multiple sclerosis in Västerbotten County in northern Sweden. J Neurol Neurosurg Psychiatry 2003, 74:29-32.

94. Svenningsson A, Runmarker B, Lycke J, Andersen O: Incidence of MS during two fifteen-year periods in the Gothenburg region of Sweden. Acta Neurol Scand 1990, 82:161-168.

95. Bostrom I, Callander M, Kurtzke JF, Landtblom AM: High prevalence of multiple sclerosis in the Swedish county of Varmland. Multiple sclerosis 2009, 15(11):1253-1262. 
96. Bentzen J, Flachs EM, Stenager E, Bronnum-Hansen H, Koch-Henriksen N: Prevalence of multiple sclerosis in Denmark 1950-2005. Multiple sclerosis 2010, 16(5):520-525.

97. Eaton WW, Pedersen MG, Atladottir HO, Gregory PE, Rose NR, Mortensen PB: The prevalence of 30 ICD-10 autoimmune diseases in Denmark. Immunol Res 2010, 47(1-3):228-231.

98. Eaton WW, Rose NR, Kalaydjian A, Pedersen MG, Mortensen PB: Epidemiology of autoimmune diseases in Denmark. J Autoimmun 2007, 29(1):1-9.

99. Koch-Henriksen N: The Danish Multiple Sclerosis Registry: a 50-year follow-up. Multiple sclerosis 1999, 5(4):293-296.

100. Sarasoja T, Wikstrom J, Paltamaa J, Hakama M, Sumelahti ML: Occurrence of multiple sclerosis in central Finland: a regional and temporal comparison during 30 years. Acta Neurol Scand 2004, 110(5):331-336.

101. Benedikz J, Magnússon H, Guõmundsson G: Multiple sclerosis in Iceland, with observations on the alleged epidemic in the Faroe Islands. Ann Neurol 1994, 36(S2):S175-S179.

102. Benedikz J, Magnússon H, Poser CM, Benedikz E, Olafsdottir G, Gudmundsson G: Multiple sclerosis in Iceland 1900-1985. J Trop and Geogr Neurol 1991, 1:16-22.

103. Benedikz J, Stefánsson M, Guõmundsson J, Jónasdóttir A, Fossdal R, Gulcher $J$, Stefánsson K: The natural history of untreated multiple sclerosis in Iceland. A total population-based 50 year prospective study. Clin Neurol Neurosurg 2002, 104:208-210.

104. Joensen P: Multiple sclerosis incidence in the Faroe Islands 1986-2007. Acta Neurol Scand 2010, 121(5):348-353.

105. De Sa J, Paulos A, Mendes H, Becho J, Marques J, Roxo J: The prevalence of multiple sclerosis in the District of Santarem, Portugal. J Neurol 2006, 253(7):914-918

106. Ares B, Prieto JM, Lema M, Dapena D, Arias M, Noya M: Prevalence of multiple sclerosis in Santiago de Compostela (Galicia, Spain). Mult Scler 2007, 13:262-264.

107. Benito-Léon J, Martin E, Vela L, Villar ME, Felgueroso B, Marrero C, Guerrero A, Ruiz-Galiana J: Multiple sclerosis in Mbstoles, central Spain. Acta Neurol Scand 1998, 98:238-242.

108. Bufill E, Blesa R, Galan I, Dean G: Prevalence of multiple sclerosis in the region of Osona, Catalonia, northern Spain. J Neurol Neurosurg Psychiatry 1995, 58:577-581.

109. Fernandez O, Fernandez V, Martinez-Cabrera V, Mayorga C, Alonso A, Leon A, Arnal C, Hens M, Luque G, de Ramon E, et al: Multiple sclerosis in Gypsies from southern Spain: prevalence, mitochondrial DNA haplogroups and HLA class II association. Tissue Antigens 2008, 71(5):426-433.

110. Fernandez O, Luque G, San Román C, Bravo M, Dean G: The prevalence of multiple sclerosis - in the Sanitary District of Vélez-Malaga, southern Spain. Neurology 1994, 44:425-429.

111. Modrego Pardo PJ, Pina Latorre MA, López A, Errea JM: Prevalence of multiple sclerosis in the province of Teruel, Spain. J Neurol 1997, 244:182-185.

112. Modrego PJ, Pina MA: Trends in prevalence and incidence of multiple sclerosis in Bajo Aragón, Spain. J Neurol Sci 2003, 216(1):89-93.

113. Pina MA, Ara JR, Modrego PJ, Morales F, Capablo JL: Prevalence of multiple sclerosis in the sanitary district of Calatayud, Northern Spain: is Spain a zone of high risk for this disease? Neuroepidemiology 1998, 17:258-264.

114. Tola MA, Yugueros MI, Fernández-Buey N, Fernández-Herranz R: Prevalence of multiple sclerosis in Valladolid, northern Spain. J Neurol 1999, 246:170-174.

115. Uria DF, Calatayud MT, Virgala P, Diaz A, Chamizo C, Dean G: Multiple sclerosis in Gijon health district, Asturias, northern Spain. Acta Neurol Scand 1997, 96:375-379.

116. Aladro Y, Alemany MJ, Perez-Vieitez MC, Amela R, Conde M, Reyes MP, Alamo F, Angel-Moreno A: Prevalence and incidence of multiple sclerosis in Las Palmas, Canary Islands, Spain. Neuroepidemiology 2005, 24(1-2):70-75.

117. Hernandez MA: Epidemiology of multiple sclerosis in the Canary Islands (Spain): a study on the island of La Palma. J Neurol 2002, 249(10):1378-1381.

118. Casqueroa P, Villosladac P, Montalbán X, Torrent M: Frequency of multiple sclerosis in Menorca, Balearic Islands, Spain. Neuroepidemiology 2001, 20:129-133.

119. van Ooteghem $P, D^{\prime}$ Hooghe MB, Vlietinck $R$, Carton H: Prevalence of multiple sclerosis in Flanders, Belgium. Neuroepidemiology 1994, 13:220-225.

120. Debouverie M, Pittion-Vouyovitch S, Louis S, Roederer T, Guillemin F: Increasing incidence of multiple sclerosis among women in Lorraine, Eastern France. Multiple sclerosis 2007, 13(8):962-967.

121. Moreau T, Manceau E, Lucas B, Lemesle M, Urbinelli R, Giroud M: Incidence of multiple sclerosis in Dijon, France: a population-based ascertainment Neurol Res 2000, 22:156-159.
122. Sagnes-Raffy C, Gourraud P-A, Hannon V, Bourrel R, Laffontan M-A, Gaulene M-C, Viala F, Clanet M: La SEP en Haute-Garonne: une sous-estimation importante du nombre de cas. Rev Epidemiol Sante Publique 2010, 59:23-31.

123. Fromont A, Binquet C, Sauleau EA, Fournel I, Bellisario A, Adnet J, Weill A Vukusic S, Confavreux C, Debouverie M, et al: Geographic variations of multiple sclerosis in France. Brain 2010, 133(Pt 7):1889-1899.

124. Beer S, Kesselring J: High prevalence of multiple sclerosis in Switzerland. Neuroepidemiology 1994, 13:14-18.

125. Poser S, Stickel B, Krtsch U, Burckhardt D, Nordman B: Increasing incidence of multiple sclerosis in south lower Saxony, Germany. Neuroepidemiology 1989, 8:207-213.

126. Fasbender $\mathrm{P}$, Kolmel HW: Incidence of multiple sclerosis in the urban area of Erfurt, Thuringia, Germany. Neuroepidemiology 2008, 30(3):147-151.

127. Baumhackl U, Eibl G, Ganzinger U, Hartung HP, Mamoli B, Pfeiffer KP, Fazekas F, Vass K, Committee AMS: Prevalence of multiple sclerosis in Austria; results of a nationwide survey. Neuroepidemiology 2002, 21:226-234.

128. Bencsik K, Rajda C, Füvesi J, Klivényi $P$, Járdánházy $T$, Török $M$, Vécsei L: The prevalence of multiple sclerosis, distribution of clinical forms of the disease and functional Status of patients in Csongrád County, Hungary. Eur Neurol 2001, 46:206-209.

129. Bencsik K, Rajda C, Klivényi $P$, Járdánházy $T$, Vécsei L: The prevalence of multiple sclerosis in the Hungarian city of Szeged. Acta Neurol Scand 1998, 97:315-319.

130. Sepcic J, Antonelli L, Materljan E, Sepic-Grahovac D: Multiple sclerosis cluster in Gorski Kotar, Croatia, Yugoslavia. In Multiple sclerosis research: proceedings of the International Multiple Sclerosis Conference-an update on Multiple Sclerosis. Edited by Battaglia MA. Amsterdam: Excerpta Medica; 1989:165-169.

131. Pekmezovic T, Jarebinski M, Drulovic J, Stojsavljevic N, Levic Z: Prevalence of multiple sclerosis in Belgrade, Yugoslavia. Acta Neurol Scand 2001, 104:353-357.

132. Dobec-Meić B, Puljić I: Incidence of multiple sclerosis in the Varaždin County. Neurol Croat 2007, 56(1-2):17-24.

133. Dobec-Meić B, Puljić I, Kalousek M: Prevalence of multiple sclerosis in Varaždin Region. Neurol Croat 2008, 57(1-2):3-9

134. Peterlin B, Ristic S, Sepcic J, Vracko BK, Rako A, Lovrecic L, Brajenovic-Milic B, Rudez J, Materljan E, Kapovic M: Region with persistent high frequency of multiple sclerosis in Croatia and Slovenia. J Neurol Sci 2006, 247(2):169-172.

135. Klupka-Sarić I, Galić M: Epidemiology of multiple sclerosis in Western Herzegovina and Herzegovina - Neretva Canton, Bosnia and Herzegovina. Coll Antropol 2010, 34(S1):189-193.

136. Klupka-Saric I, Ristic S, Sepcic J, Kapovic M, Peterlin B, Materljan E, Jurisic T, Mamic DM, Burina A, Sulentic V: Epidemiology of multiple sclerosis in western Herzegovina. Clin Neurol Neurosurg 2007, 109(9):779-783.

137. Milanov I, Georgiev D, Kmetska K, Jordanova L, Topalov N: Prevalence of multiple sclerosis in Bulgaria. Neuroepidemiology 1997, 16:304-307.

138. Papathanasopoulos P, Gourzoulidou E, Messinis L, Georgiou V, Leotsinidis M: Prevalence and incidence of multiple sclerosis in western Greece: a 23-year survey. Neuroepidemiology 2008, 30(3):167-173.

139. Piperidou HN, Heliopoulos IN, Maltezos ES, Milonas IA: Epidemiological Data of Multiple Sclerosis in the Province ofEvros, Greece. Eur Neurol 2003, 49(1):8-12.

140. Gross K, Kokk A, Kaasik A-E: Prevalence of MS in South Estonia. Evidence of a new border of the Fennoscandian locus. Acta Neurol Scand 1993, 88:241-246

141. Koutsouraki E, Costa V, Baloyannis S: Epidemiology of multiple sclerosis in Europe: a review. Int Rev Psychiatry 2010, 22(1):2-13.

142. Pugliatti M, Rosati G, Carton H, Riise T, Drulovic J, Vecsei L, Milanov I: The epidemiology of multiple sclerosis in Europe. Eur J Neurol 2006, 13(7):700-722

143. Rosati G: Descriptive epidemiology of multiple sclerosis in Europe in the 1980s: a critical overview. Ann Neurol 1994, 36(S2):S164-S174.

144. Culpepper W, Ehrmantraut M, Wallin M, Flannery K, Bradham D: Veterans Health Administration multiple sclerosis surveillance registry: the problem of case-finding from administrative databases. J Rehabil Res Dev 2006, 43:17-24.

145. Marrie R, Yu N, Blanchard J, Leung S, Elliot L: The rising prevalence and changing age distribution of multiple sclerosis in Manitoba. Neurology 2010, 74:465-471.

146. Simpson S Jr, Blizzard L, Otahal P, Van der Mei I, Taylor B: Latitude is significantly associated with the prevalence of multiple sclerosis: a metaanalysis. J Neurol Neurosurg Psychiatry 2011, 82:1132-1141. 
147. Esbjerg S, Keiding N, Koch-Henriksen N: Reporting delay and corrected incidence of multiple sclerosis. Stat Med 1999, 18(13):1691-1706.

148. Marrie RA, Cutter G, Tyry T, Hadjimichael O, Campagnolo D, Vollmer T: Changes in the ascertainment of multiple sclerosis. Neurology 2005, 65(7):1066-1070.

149. Kingwell E, Leung AL, Roger E, Duquette P, Rieckmann P, Tremlett H, The MS: Clinic Neurologists: Factors associated with delay to medical recognition in two Canadian multiple sclerosis cohorts. J Neurol Sci 2010, 292:57-62.

150. Zivadinov R, lona L, Monti-Bragadin L, Bosco A, Jurjevic A, Taus C, Cazzato $\mathrm{G}$, Zorzon M: The use of standardized incidence and prevalence rates in epidemiological studies in multiple sclerosis: a meta-analysis study. Neuroepidemiology 2003, 22:65-74.

doi:10.1186/1471-2377-13-128

Cite this article as: Kingwell et al: Incidence and prevalence of multiple sclerosis in Europe: a systematic review. BMC Neurology 2013 13:128.

\section{Submit your next manuscript to BioMed Central and take full advantage of:}

- Convenient online submission

- Thorough peer review

- No space constraints or color figure charges

- Immediate publication on acceptance

- Inclusion in PubMed, CAS, Scopus and Google Scholar

- Research which is freely available for redistribution 